\section{DARK AGE AHEAD}

Jane Jacobs

New York: Random House, 2004. 240p.

\section{Lilian Fessler Vaz (Prourb/FAU/UFRJ)}

Em 1961 Jane Jacobs publicou Morte e vida das grandes cidades norte-americanas, abalando os princípios do urbanismo e do planejamento urbano moderno. Aos 88 anos, Jacobs volta à cena com um livro polêmico e extremamente atual. Com sua atitude corajosa e enfoque crítico, utilizando-se de uma linguagem clara e de conceitos compreensíveis, a autora criou uma obra acessível a um vasto público interessado em questôes contemporâneas. Dark Age Ahead nos alerta que a cultura norte americana, e, por extensão, a cultura ocidental, se encontra no limiar de uma nova Idade das Trevas.

Muitos povos neste planeta, e não apenas os que constituíram o império romano, assistiram ao declínio de suas culturas e ao mergulho em uma Idade das Trevas. Consta que esta fase é anunciada pelos quatro cavaleiros do apocalipse - a fome, a guerra, a peste e a morte, aos quais Jane Jacobs acrescenta mais um: o esquecimento. Com a decadência da cultura e a perda de memória, ou melhor, com a amnésia em massa, os saberes e os fazeres dos povos desaparecem. E o que se perde, não se recupera mais.

Muitos países procuram preservar suas culturas. Registram e arquivam imenso volume de dados sobre as culturas, através dos mais diversos meios - livros, fotografias, filmes, discos, ou outros, em ambientes fechados e protegidos, buscando assegurar a sua permanência. Mas a sensação de segurança assim obtida é falsa: as culturas são vivas e complexas, se transmitem e são assimiladas essencialmente através da palavra falada, do exemplo observado, da experiência vivida, da educação recebida.

A partir destas considerações iniciais, Jacobs aponta indícios das trevas que se avizinham. Embora ela não faça referências específicas ao mal-estar da pósmodernidade, à desumana polarização social, à crescente violência urbana, ou à degradação do meio ambiente, estas percepções da contemporaneidade permeiam todo o livro. Para a autora, os sinais da decadência podem ser percebidos em cinco pilares sobre os quais se apóia a cultura norte-americana: comunida- de e família, educação superior, ciência e tecnologia, tributação e governo, e auto-regulação profissional. A degradação de cada um destes pilares é analisada e discutida em um capítulo específico.

Apesar destes pilares não serem, aparentemente, temas dos estudos urbanos, a argumentação se desenvolve essencialmente em torno das transformações do espaço e da vida urbana, como no segundo capítulo, sobre a dissolução da família e da comunidade, e no quarto capítulo, sobre o abandono da ciência. Vale a pena observar mais detidamente estes pontos.

O processo de degradação destas duas esferas da vida humana - família e comunidade - é paralelo ao aumento crescente do custo da habitação e das dificuldades de manutenção de uma moradia. Desde os anos 30, nos Estados Unidos e no Canadá, a renda média de uma família era suficiente para pagar o custo da compra de uma casa ou o aluguel de um apartamento. Mas, a partir dos anos 70, as estatísticas mostravam que apenas $10 \%$ das famílias dispunham de renda para a compra de uma casa "média". Os 90\% restantes adotavam diferentes meios para reduzir as despesas domésticas e aumentar a renda familiar, sendo o principal, lançar as mães e as esposas no mercado de trabalho. Mas as despesas domésticas aumentaram quando uma nova necessidade se impôs: o automóvel, devido ao declínio ou desaparecimento dos transportes públicos nos subúrbios. Nas cidades que se renovavam, e nos novos subúrbios, a distância entre o local de moradia e de trabalho se ampliava crescentemente, obrigando as famílias a se utilizarem do automóvel não somente para o trabalho mas para os mais diversos deslocamentos.

Segundo Jacobs, o maior destruidor das comunidades americanas não foram nem as drogas nem a televisão, mas o automóvel. A modernização por meio da renovação urbana destruiu comunidades ao arrasar bairros antigos para a passagem de highways e expressways. Estes, por sua vez, induziam a expansão, com a construção de subúrbios que se alternavam com shopping centers. Mas poucas foram as comunidades novas que se formavam, porque junto com a eliminação das antigas comunidades desaparecia também a memória do que haviam sido. Além disso, o espaço público já não propiciava mais o encontro de pessoas, um ponto fundamental na formação e na ação das comunidades. Pois muitas das demandas das populações são providas pelas comunidades, sendo as mais importantes aquelas 
totalmente intangíveis e informais, e que respondem à necessidade de contatos pessoais, de pertencimento a grupos e redes, de comunicação com o outro.

$\mathrm{O}$ impulso decisivo para este processo destruidor foi dado através dos persistentes ataques corporativos aos sistemas de transportes públicos, uma estratégia comandada pela General Motors. A autora cita ainda nomes de políticos, de empresas e de construtores ao relatar passagens em cidades americanas que viram, no decorrer de décadas, seus eficientes sistemas de bondes, e depois, de ônibus elétricos, serem desmantelados (e a memória de sua tecnologia, perdida), a favor da disseminação irrestrita do automóvel particular.

Este ponto é retomado no quarto capítulo, em que Jacobs usa a engenharia de tráfego como um dos exemplos do abandono da ciência e da traição ao pensamento científico. Apesar do seu status científico, a engenharia e a gestão do tráfego são responsáveis não somente pela destruição das comunidades, mas também pela poluição do meio ambiente e pelo desperdício de tempo, de terra e de energia. Jacobs relata alguns movimentos de resistência de moradores à construção de expressways ou à modernização do tráfego em bairros residenciais, alegadas como necessidades inegáveis e soluçōes irrecusáveis. Mesmo depois de pesquisas terem mostrado que a construção de novas vias gera mais tráfego, os engenheiros de tráfego mantiveram durante décadas o mesmo discurso, recusando-se a admitir as evidências. Da mesma maneira, nos outros exemplos, médicos e economistas não compreendiam fenômenos ocorridos porque não conseguiam se livrar de pensamentos pré-elaborados nem ver o que a cidade e a vida dos seus moradores lhes apresentavam.

Os exemplos ilustram não somente os desvios do pensamento científico, mas também uma das conseqüências da educação superior. Este é o tema do quarto capítulo, que mostra como o ensino foi sendo menosprezado, e o credenciamento, privilegiado. Este é o termo usado pela autora para designar o sistema de produção de títulos e diplomas, vistos como garantia de trabalho e segurança no futuro. A ilusão do pleno emprego incentivou a proliferação de escolas superiores e de universidades; mas, à medida que o sistema de produção de diplomas se expandia em quantidade, a educação declinava em qualidade.

O quinto capítulo mostra que há uma crescente desconexão entre os recursos recolhidos através de taxas $\mathrm{e}$ impostos e o atendimento às necessidades dos seus pagadores. À medida que os princípios da subsidiaridade e da responsabilidade fiscal eram abandonados, que as políticas neo-conservadoras, as parcerias público-privadas, e as reformas econômicas demandadas pelo FMI se impunham, novos critérios para a distribuição de recursos eram adotadas. A crescente desassociação entre pagamento de tributos e o seu retorno como provisão das demandas da população é analisada no caso canadense, refletindo-se na degradação da vida urbana, através do crescente encarecimento da moradia, da proliferação dos sem-teto, do agravamento da poluição, da decadência dos mais diversos serviços públicos. Além da irresponsabilidade dos governos, Jacobs critica a irresponsabilidade de algumas categorias profissionais, como os da área contábil, tema do sexto capítulo.

O tema da decadência de uma cultura permite inúmeras abordagens, a partir dos mais variados aspectos. Escolher a ruína dos cinco pilares da cultura norte-americana é certamente um enfoque ousado que dará margem a críticas, como a de que as transformaçōes apontadas não necessariamente levam à uma nova Idade das Trevas. Mas, no que diz respeito à cidade, à vida urbana e à cultura urbana, o olhar e a leitura de Jane Jacobs é fundamental para todos que se interessam pelos estudos urbanos.

É justamente para este segmento de leitores que uma outra leitura se destaca: uma crítica vigorosa ao modo de urbanização norte-americano, ao sprawl, e, por extensão, à cidade difusa, suburbana, genérica. Como o objeto privilegiado de observação de Jacobs é a cidade, e nela, o ponto mais crítico é a expansão suburbana, suas causas e conseqüências, delineia-se um discurso contra esta modalidade urbana contemporânea, que se explicita no sétimo capítulo, em que Jacobs indica como desfazer os círculos viciosos que alimentam este processo de expansão.

A crítica ao sprawl se apresenta habitualmente confrontando a cidade dispersa à cidade histórica, central, consolidada, apontando as vantagens desta sobre aquela. Apontam-se na cidade difusa a falta de historicidade, de identidade, de centralidade, de espaços efetivamente públicos, assim como a predominância do transporte particular e o consumo excessivo do território, com a perda de espaços verdes. Novamente Jane Jacobs surpreende com um discurso diferente, que mostra a formação dos subúrbios, os diferentes interes- 
ses envolvidos neste processo, o modo como as ações engendradas modificaram o espaço e o cotidiano das populações moradoras, seus corações e suas mentes. Percebendo e articulando o material e o simbólico, buscando elos e tecendo conexóes, dando sentido a fatos, fenômenos e processos aparentemente díspares, a autora interpreta e explica tranformaçôes da cidade e da cultura urbana.

Um novo marco da bibliografia sobre a cidade? $\mathrm{Ou}$ apenas um novo livro saudosista? Ingênuo? Pessimista? Superficial? Só com o tempo poderemos avaliar o valor do alerta de Jane Jacobs. E o tempo, ao menos durante os 43 anos decorridos da publicação de Morte e vida das grandes cidades norte-americanas, só fez mostrar a sensibilidade, a atualidade e o acerto do pensamento desta jornalista apaixonada pelas cidades.

\section{DU CONTRE-POUVOIR. DE LA SUBJECTIVITÉ CONTESTATAIRE À LA CONSTRUCTION DE CONTRE-POUVOIRS}

Miguel Benasayag e Diego Sztulwark La Découverte: Paris, 2000. 167p.

Marcelo Calazans (Ippur/UFRJ)

"Do contra-poder" surpreende por abordar a questão da política e do poder, sem no entanto centrarse no debate sobre o Estado. Na contra-corrente das duas últimas décadas de desideologização da política, de sua transformação em estratégias partidárias de marketing e de sua tecnificação em planos de controle e gestão estatal, os autores retomam o debate do poder desde a perspectiva da sociedade civil, de suas redes e movimentos sociais.

Deslocando-se pelo eixo Europa-América Latina e buscando afirmar um horizonte temporal pós 19801990, "Do contra-poder" articula mobilizações sociais no México (zapatistas), no Brasil (sem-terra), na Argentina (mães da Praça de Maio) e na Europa (Attac, Act Up, coletivos antiexpulsão etc.), percebendo neste conjunto a emergência de uma "contra-ofensiva" e de uma "nova radicalidade" política.

A datação historiográfica talvez não corresponda por completo ao processo histórico singular em cada país e continente. Por exemplo: os anos 1980, nos países do Sul, vistos como período de "abertura política" e "esgotamento das ditaduras militares", estariam mais próximos da experiência dos movimentos "libertários" dos anos 1960-1970 no Norte. Talvez nessa primeira década do século XXI, em Buenos Aires ou Brasília, a prática política não tenha se diferenciado da que vigorava nos anos 90. Talvez a "nova radicalidade" e a "contra-ofensiva” sejam ainda algo por vir, ao menos como gostariam os autores. Náo importam tanto aqui as datas. Compreendemos bem o que querem dizer quando se referem aos anos 80 e 90 como "anos pós-revolucionários", anos do "conformismo resignado" e do "neo-liberalismo como horizonte intransponível". De fato, os sentimentos de frustração e impotência política ganharam o cotidiano das sociedades ocidentais. Para além da precisão das datas, as décadas de desmobilização social atuaram na desconstrução de um mito histórico, da 